Leclercq, P., \& Edmonds, A. (2017). How L2 learners of French and English express modality using verbal means: A crosslinguistic and developmental study. International Review of Applied Linguistics in Language Teaching, 55(3), 265-282.

\title{
How L2 learners of French and English express modality using verbal means: A crosslinguistic and developmental study
}

\begin{abstract}
This study describes and analyzes how native and non-native speakers express modality using verbal means during oral retellings. Participants included native speakers of French and English, as well as English-speaking learners of French and French-speaking learners of English at three levels of language proficiency. All participants performed the same short film retelling, which was then transcribed and analyzed in terms of modalization. Results show that all groups use verbal modal means, although rates, meanings and types of modal forms used vary across the two languages, and especially as a function of second language proficiency.
\end{abstract}

\section{Introduction}

According to Choi (2006: 141), "by using some modal expressions, speakers state more than just what they see: with modal forms speakers can add their own or other people's psychological or mental states regarding the proposition." Modality is therefore a key semantic domain in communication, and more specifically in the expression of speakers' stance. Within a second language (L2) approach, Giacalone Ramat (1995: 272) states that "to modalize a communicative content is a primary necessity for all learners." However, while the expression of tense and aspect in interlanguage has received considerable attention, research into the expression of modality in an L2 has lagged behind (Bardovi-Harlig (2000); Howard and Leclercq (2017).

In the current project, we seek to contribute to this area of research with an analysis of modalization (i.e., the way speakers qualify an event with grammatical markers) in a narrative corpus, with a specific focus on verbal means of modalization (modality and mood). We will take both a crosslinguistic and developmental perspective, thus complementing existing literature with an analysis of the different verbal modal forms used in oral film retellings by 10 French and 10 English native speakers (NS) as control groups, as well as by French learners of English and English-speaking learners of French (5 lower intermediate, 5 upper intermediate, 5 advanced learners per language). This approach will allow us to determine whether the use of such forms characterizes the narrations of the different participants and whether their use changes as a function of proficiency level.

\section{Theoretical framework}

Despite a large body of theoretical work on modality, authors do not fully agree on what modality is or how it is marked (von Stutterheim 1993; de Haan 2006; Nuyts 2006). This is at 
least in part due to the fact that the concept of modality can be difficult to circumscribe. Although the concept seems to be universal, the categories through which modalization can be realized vary across languages (Choi 2006; de Haan 2006), including intonation, adverbs, adjectives, nouns, mood, mental verbs, modal verbs and auxiliaries. To frame our analysis, we will present only those modality concepts directly relevant to our study. We begin with a general review of modality before looking more specifically at the expression of modality through verbal modal markers in French and in English.

\subsection{Modal vs. non-modal}

The concept of modalization was developed in contrast with neutral (or non-modal) means of expression. Ducrot (1993:112-3) notes that the opposition between modal and non-modal, which corresponds in traditional western thought to the distinction between objective and subjective, is at the heart of the modality concept: Describing a state of affairs (non-modal) is distinct from taking position or commenting on the same state of affairs (modal). Ducrot goes on to specify that, to some extent, choosing to present events in a "neutral" way already corresponds to a chosen stance, with speakers' intentions and motivations being represented in their choice of both modalized and non-modalized speech.

\subsection{How modalization is expressed: Mood and modality}

In research on modalization, mood is generally distinguished from modality. Bybee and Fleischman (1995: 2) define mood as a grammaticalized category of the verb with a modal function (ex. indicative, subjunctive, imperative...), and modality as a semantic domain providing the "addition of a supplement or overlay of meaning to the most neutral semantic value of the proposition of an utterance, namely factual and declarative". Moreover, they remind us that mood and modality are not mutually exclusive, as shown in the following example from our corpus:

$$
\begin{aligned}
& \text { pour qu'il puisse enlever le manteau. } \\
& \text { 'so he can-SUBJ take off the coat' } \\
& \text { (NAD, FRL1, utt } 66 \text { ) }
\end{aligned}
$$

In (1), the goal subordinate clause introduced by pour que features a modal auxiliary, pouvoir, in the present subjunctive, before the infinitive main verb enlever. Our analysis will take into account both of these types of modalization: verb modal markers (like pouvoir) and mood (e.g., the use of the subjunctive in French).

\subsection{Modal categories}

It is generally recognized that modality covers two broad semantic categories: Epistemic modality relates to the validity of utterances (i.e., their truth value), while deontic modality is "concerned with the necessity or possibility of acts performed by morally responsible agents (Lyon 1977: 823), and is thus associated with the social functions of permission and 
obligation" (Bybee \& Fleischman 1995: 4). ${ }^{1}$ While the epistemic category is fairly uncontroversial, the description and scope of other modal categories (such as deontic, root, or agent-oriented modality) varies in the literature (see Nuyts [2006] for a thorough review). For the purposes of the current study, we have adopted Biber et al.'s classification, which distinguishes between personal and logical modal meanings:

Personal (intrinsic) modal meaning refers to the control of actions and events by human and other agents. These meanings are personal permission, obligation, and volition (or intention). Logical (extrinsic) modal meaning refers to the logical status of states or events. It usually refers to levels of certainty, likelihood, or logical necessity. (Biber et al. 2002: 176-177).

Personal meanings are characterized by the fact that "the subject of the verb phrase usually refers to a human being, and the main verb is usually a dynamic verb that describes an activity or event that can be controlled" (p. 177). Examples taken from our corpus and provided in Table 1 illustrate expressions of ability (couldn't reach, manages to get off, peuvent marcher), obligation (has to throw), volition (veut récupérer), and intention (tries to walk). Logical meanings are instantiated in modal verbs whose subjects are usually non-human, although human subjects are possible when the speaker takes a stance on the certainty of the predicate. In Table 1, examples of expressions of possibility (pourrait être), certainty (I think), necessity (must have fallen, faut qu'il le mette), inference (seems to be having), and prediction (va mourir) are provided. ${ }^{2}$

\begin{tabular}{|c|c|c|}
\hline \multirow[b]{2}{*}{ Language } & \multicolumn{2}{|c|}{ Modality type } \\
\hline & $\begin{array}{l}\text { Personal } \\
\end{array}$ & Logical \\
\hline \multirow[t]{4}{*}{ English } & $\begin{array}{l}\text { and the boy - the boy still couldn't } \\
\text { reach the ehm ladder (ALX, EngL1, } \\
\text { utt 79) }\end{array}$ & $\begin{array}{l}\text { cause he sort of must have fallen over } \\
\text { or something (RIC, EngL1, utt 56) }\end{array}$ \\
\hline & $\begin{array}{l}\text { after a little while he somehow } \\
\text { manages to get off this icy patch } \\
\text { (MIC, EngL1, utt 16) }\end{array}$ & $\begin{array}{l}\text { she seems to be having a good } \\
\text { afternoon (ART, EngL1, utt 84) }\end{array}$ \\
\hline & $\begin{array}{l}\text { the dog has to throw (MIC, EngL1, utt } \\
\text { 145) }\end{array}$ & $\begin{array}{l}\text { I think it's actually the top of the } \\
\text { kennel. (SAM, EngL1, utt 22) }\end{array}$ \\
\hline & $\begin{array}{l}\text { she tries to walk around (MIC, EngL1, } \\
\text { utt 29) }\end{array}$ & \\
\hline \multirow[t]{2}{*}{ French } & $\begin{array}{l}\text { donc comme ça ils peuvent marcher } \\
\text { tranquillement devant. } \\
\text { (EGI, FrL1, utt } 33 \text { ) }\end{array}$ & $\begin{array}{l}\text { ce qui pourrait être du sel ou du sable } \\
\text { sur la flaque d'eau. } \\
\text { (EGI, FrL1, utt } 31 \text { ) }\end{array}$ \\
\hline & $\begin{array}{l}\text { 'so like that they can walk calmly } \\
\text { ahead' }\end{array}$ & $\begin{array}{l}\text { 'which could be salt or sand on the } \\
\text { puddle' }\end{array}$ \\
\hline
\end{tabular}

\footnotetext{
${ }^{1}$ Mood, on the other hand, is not generally analyzed according to these same semantic categories. See Section 2.4.1 for details on the semantic values associated with the French subjunctive mood.

${ }^{2}$ Our data were classified according to the division proposed by Biber and colleagues, except for inference, a category we created to account for examples in our data such as seem.
} 
mais bon sa maîtresse veut récupérer son patin. (NAD, FrL1, utt 97)

'but well his mistress wants to get her skate back' et bien sûr il faut qu'il le mette du bon côté. (NAD, FrL1, utt 65)

'and of course it has to be put on the right side'

qui va mourir de froid. (LIN, FrL1, utt 84)

'who is going to die of cold'

Table 1. Examples of different modality types

This classification cuts across the traditional deontic/epistemic lines: The category of logical modal meaning, for example, covers the epistemic domain, but also encompasses prediction and necessity. The use of personal versus logical modal meaning for the analysis of our corpus was relevant for two reasons. First, certain modal expressions in French do not fit well into the usual deontic/epistemic distinction. This is particularly the case for impersonal constructions (e.g., il faut que, expressing necessity). By taking into account the agentive status of subjects, the impersonal expressions of necessity or possibility that are found in French can be incorporated into our analysis. Second, the opposition between personal and logical modal meaning includes volition, intention and prediction under the umbrella of modal expression (see Nuyts [2006: 9], for a review of the discussion around volition and intention as modal categories). Thus, by following Biber et al. (2002), we were able to provide a more complete picture of verbal modal expression in our corpus.

\subsection{The modal systems of French and English}

\subsubsection{French.}

In French, modal verbs such as pouvoir 'can', devoir 'must', savoir 'know/can' and vouloir 'want' can be used as main verbs (je le veux 'I want it') as well as auxiliary modal verbs (je veux manger 'I want to eat'). They can also combine with aspect and voice. According to Ayoun (2013: 39), other verbs, such as sembler 'seem' and falloir 'have to' can be considered to express a type of modality (with logical modal meaning, in the case of the framework adopted in this article). In addition, the French verbal system includes a productive subjunctive mood, which, according to Ayoun (2013: 25), expresses three major types of concepts: "volition (commands, wishes, requirements, requests, etc.), subjectivity (in judgment, opinion, belief, etc.) and doubt". However, subjunctive use is largely constrained by contextual factors, leading certain linguists to claim in modern French the subjunctive simply indicates subordination (see Lepetit [2000]) and is restricted to a small number of lexically defined contexts (Poplack, Lealess and Dion 2013). Finally, the concept of volition may also be expressed through the conditional mood (il aimerait bien venir 'he would like to come').

\subsubsection{English.}

The English modal system includes nine modal verbs (can, could, may, might, should, will, would, shall), which are invariable, do not carry agreement or tense morphological markings, 
and are followed by a bare infinitive verb form. The system also includes semi-modals, some of which (such as have to or be going to) take tense and person inflections. Both modals and semi-modals can combine with aspect and voice, as can be seen in the example of logical modality given in Table 1: cause he sort of must have fallen over or something (RIC, EngL1, utt 56). In addition to these devices, other verbal expressions may also express modal meanings, including volition (want), intention (decide), obligation (be obliged to), possibility (be likely to), or inference (seem) without sharing the syntactic properties of modals.

\section{L2 acquisition of mood and modality}

Some of the earliest work on the L2 acquisition of mood and modality concentrated on the very early stages of learning a foreign language. For example, Dittmar (1993) focused on proto-modality and on the emergence of modality markers in the speech of migrants learning German, while Stoffel and Véronique (1993) studied the early stages of L2 French. Work in a similar vein was carried out by Giacalone Ramat (1995) on Italian, by Ahrenholz (2000) on German and, in an instructional context, by Gibbs (1995) and Salsbury and Bardovi-Harlig (2000) for English. Results show that learners in the first stages of L2 acquisition rely on pragmatic means and their interlocutor's capacity to reconstruct modal intentions through inference. Use of explicit modal markers increases with time, with modal adverbials occurring later than verbs. Epistemic markers appear at later stages or not at all. Moreover, there seems to be general agreement that the expression of deontic modal meanings (e.g., obligation and permission) precede epistemic ones, just as in first language acquisition (Stephany 1993; Choi 2006; see Stephany [1995] for the potential importance of discourse type in the emergence of modality markers in L2 acquisition).

In addition to this body of research on the expression of modality, specific sub-parts of the modality spectrum have attracted attention in recent years. These include the subjunctive mood in French (Bartning 2005; Howard 2008, Howard 2012; Ayoun 2013; McManus and Mitchell 2015) and the acquisition of means of reference to the future in English (BardoviHarlig 2002) and in French (Howard 2012; Ayoun 2013; Edmonds and Gudmestad 2015). Results from these studies show consistently that the subjunctive mood in French is a lateacquired feature and that its use is largely restricted to certain lexical contexts (notably with falloir). With respect to the expression of futurity, results point to learners' overreliance on will in English and the inflectional future in French, even at high levels of proficiency.

This previous research indicates that while the expression of modality emerges early, though not necessarily with target modality markers, the expression of mood develops relatively late in interlanguage. However, these conclusions are largely based on interview and discussion data collected from early-stage learners. In the current study, we extend the range of proficiency levels under study, notably including intermediate and advanced learners in our corpus. In addition, given that modalization profiles vary on the basis of context (Bybee and Fleischman 1995; Biber et al. 2002), in the current project, we examine how NSs and nonnative speakers (NNSs) modalize when retelling a story, an understudied context of 
communication (cf. von Stutterheim [1993] for an analysis of modalization in a narration task). The following two research questions guided our study:

- Do NSs and intermediate and advanced NNSs of French and English use modality when performing a story retelling task? If so, what type of modality is expressed and what verbal means are used to express it?

- For the NNSs, does the expression of modality vary as a function of proficiency level?

\section{Method}

\subsection{Data collection}

We used a film retelling task eliciting narrative discourse. The stimulus was the five-minute long Reksio cartoon (Watorek 2004) featuring a dog and his master. The task instruction was: "Watch the cartoon and then tell the interviewer what happened". The task therefore involved watching the cartoon and memorizing the events with the aim of telling the story to the interviewer. The oral productions were recorded and transcribed using CLAN procedures.

Our database comprises a total of 50 participants, divided as follows:

\begin{tabular}{lllll}
\hline & & \multicolumn{2}{c}{ Gender } \\
\cline { 4 - 5 } Language & Group & Age & M & F \\
\hline English & NNSs & & & \\
& Lower intermediate $(n=5)$ & 24 & 1 & 4 \\
& Upper intermediate $(n=5)$ & 20 & 1 & 4 \\
& Advanced $(n=5)$ & 27.2 & 4 & 1 \\
& NSs $(n=10)$ & 25.4 & 5 & 5 \\
French & NNSs & & \\
& Lower intermediate $(n=5)$ & 20.8 & & 5 \\
& Upper intermediate $(n=5)$ & 22.2 & 2 & 3 \\
& Advanced $(n=5)$ & 26.2 & 2 & 3 \\
& NSs $(n=10)$ & 30.3 & 6 & 4 \\
\hline
\end{tabular}

Table 2. Presentation of participants

All groups of participants were recorded in French universities, apart from the English natives group, who were recorded in Cambridge but came from different Anglophone countries. English learners of French also came from a variety of countries (Australia, Ireland, UK, US).

Learners completed a proficiency test: Learners of English did a version of the Oxford Quick Placement test, while learners of French took a version of the placement test developed by the American University of Paris. Both tests are based on discrete-point grammar and vocabulary questions. Participants scored across four levels: lower intermediate, upper intermediate, 
advanced and very advanced. ${ }^{3}$ For the purpose of this study, we grouped advanced and very advanced speakers.

\subsection{Data coding and analysis}

Our database comprises a total of 3234 utterances, defined on the principle that one verb corresponds to one utterance, except when a modal expression precedes the main predicate:

(2) we can see the boy/drinking some tea (2 utterances)

(3) he tries to walk (1 utterance)

Data coding focused on the following variables: modalization (presence, absence), modalization type (personal, logical, mood), and modal semantics (ability/possibility, necessity, inference...). Note that most examples of the subjunctive mood (such as vienne in Table 3a) were not coded for modal semantics (see footnote 1). Exceptions to this were modal verbs used in the subjunctive. Thus, for the example provided in (1) - pour qu'il puisse enlever le manteau - the modalization type of the subjunctive form puisse of the modal verb pouvoir 'can' was coded as both Mood (for the subjunctive) and Personal meaning (for the use of pouvoir). The modal semantics of pouvoir in this case was judged to be ability/possibility. Examples of short passages for two NSs of French and a NS of English are provided in Tables $3 a$ and $3 b$.

\begin{tabular}{llccc}
\hline Speaker & Utterance & Modalization & Type & Modal semantics \\
\hline EGI & $\begin{array}{l}\text { enfin il tourne son dos face à } \\
\text { son maître. }\end{array}$ & Absence & & \\
& $\begin{array}{l}\text { 'finally he turns his back to his } \\
\text { master' }\end{array}$ & & & \\
EGI & $\begin{array}{l}\text { qui aimerait bien. } \\
\text { 'who would like' } \\
\text { qu'il vienne patiner avec lui. }\end{array}$ & Presence & Personal & Volition \\
EGI & Presence & Mood & \\
& 'that he come skate with him' & & & \\
\hline
\end{tabular}

Table 3a. Examples of coding from French NS corpus.

\begin{tabular}{llccc}
\hline Speaker & Utterance & Modalization & Type & Modal semantics \\
\hline NAT & and the ice broke again & Absence & & \\
NAT & $\begin{array}{l}\text { and she was back in the water } \\
\text { so she must have been yelling for }\end{array}$ & Absence & & \\
NAT & Presence & Logical & Necessity \\
& {$[\ldots]$} & & \\
NAT & and ehm he he gestured to her & Absence & & \\
NAT & to come out & Absence & & \\
NAT & but she couldn't & Presence & Personal & Ability/possibility \\
\hline
\end{tabular}

Table 3b. Examples of coding from English NS corpus.

\footnotetext{
${ }^{3}$ While the OQPT is a standardized test, the placement test of the AUP is not. Both tests are comparable in their conception as they both test grammatical and lexical knowledge through multiple choice questions, but while the attribution of proficiency level is well calibrated in the OQPT, proficiency level as a result of the AUP test was determined independently by the authors. We recognize that this means that the proficiency groups for the two languages may not be perfectly matched.
} 
To respond to our two research questions, we first examined the corpus in order to determine whether all groups used modalized verb forms. We then concentrated on those modalized verb forms found in the dataset and analyzed them according to type (personal, logical, mood). Finally, we looked at modal semantics expressed by each example of personal and logical modality and at the inventories of modal forms used. At each stage of the analysis, we looked for potential development across proficiency levels and compared findings from the NNS portions of our corpus to the NS narratives. Given the exploratory nature of this study and the relatively small number of occurrences for certain groups, we chose a qualitative approach supported by descriptive statistics to account for the phenomena under scrutiny.

\section{Results}

Figure 1 provides a global picture of the presence of modal verb forms in the native and nonnative portions of our corpus (see Table 4 for group-specific details). Non-modalized utterances are the rule for all groups, as is to be expected in a narrative task. Results for the French NSs, the English NSs and the learners of English are quite similar: In each case, between $13.8 \%$ and $14 \%$ of all utterances are modalized. Modalization occurs clearly less in the French NNS corpus, with only $6.6 \%$ of all utterances including a verbal expression of modality. This finding suggests that the acquisition of the French modal system may pose specific challenges, insofar as it implies both selecting a relevant modal semantic content and using appropriate verbal morphology (an additional difficulty which learners of English face to a lesser extent due to the properties of English modals).

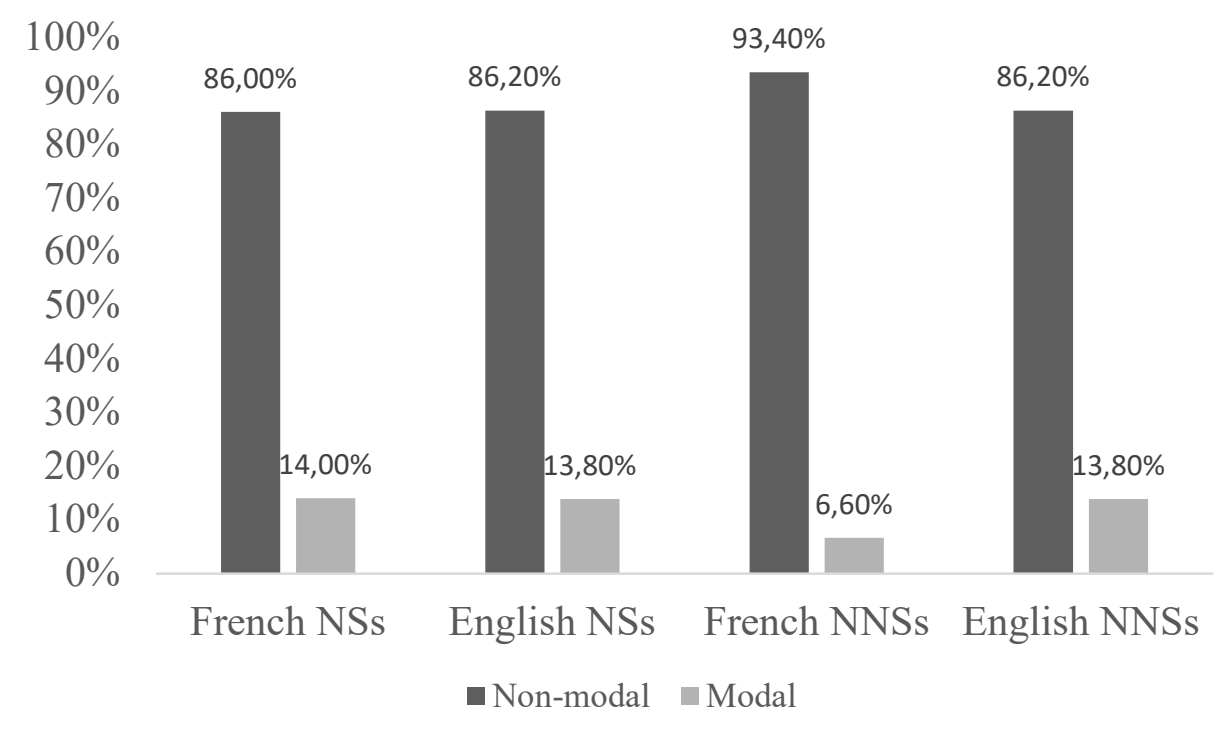

Figure 1. Percentage of modalized and non-modalized utterances.

Focusing now on the instances of modalization, we find a total of 409 modalized utterances in our full corpus. The distribution of these forms across our eight groups is presented in Table 4. While learners of French use few modal verb forms, they display a steady increase in usage, with lower intermediates each using on average 0.4 modalized forms, upper 
intermediates using an average of 2.2 forms, and advanced learners using 4.6 such forms in their narratives. Despite this increase, the highest proficiency group is still a long way from the mean use of 12 modalized forms found in the French NSs' narratives. A one-way ANOVA with group as the between-subjects factor showed the proportion of modalized utterances to differ significantly across the four groups $\left(F(3,21)=5.775, p=.005, \eta^{2}=.452\right)$. Learners of English use modal verb forms more frequently at all levels (93 occurrences in total for learners of English vs. 36 for learners of French). Unlike the learners of French, the pattern in the L2 English data does not suggest a linear increase with proficiency, and no significant difference was seen across groups $(F(3,21)=.083, p=969)$ : Lower intermediate learners use slightly more modals (mean use 5.6) than upper intermediate learners (mean use 5.2). Moreover, the overall percentage of modalized utterances is clearly higher in the lower intermediates' narratives $(28 / 174=16.1 \%)$ than in the retellings from the upper intermediates $(26 / 224=11.6 \%)$. Advanced speakers use modalized forms the most frequently (mean use 7.8) while being still quite far from matching NSs' mean use (16). Finally, it bears note that the range of use of modalized utterances shows much variation (see also the high SD per group). Given that modalization reflects a choice of perspective on the part of the speaker, it is not surprising that individuals vary widely in their use of such forms, and that certain narratives, even among the NSs, include very few.

\begin{tabular}{llccccc}
\hline Language & Group & $\begin{array}{c}\text { Total } \# \\
\text { utterances }\end{array}$ & $\begin{array}{c}\# \text { of } \\
\text { occurrences }\end{array}$ & $\begin{array}{c}\text { M use by } \\
\text { speaker }\end{array}$ & SD & Range \\
\hline English & NNSs & & & & & \\
& Lower intermediate $(n=5)$ & 174 & 28 & 5.6 & 3.7 & $1-10$ \\
& Upper intermediate $(n=5)$ & 224 & 26 & 5.2 & 1.4 & $2-7$ \\
& Advanced $(n=5)$ & 278 & 39 & 7.8 & 5.8 & $0-16$ \\
& NSs $(n=10)$ & 1158 & 160 & 16 & 6.6 & $5-34$ \\
French & NNSs & & & & & \\
& Lower intermediate $(n=5)$ & 97 & 2 & 0.4 & 0.5 & $0-1$ \\
& Upper intermediate $(n=5)$ & 197 & 11 & 2.2 & 2.3 & $0-8$ \\
& Advanced $(n=5)$ & 249 & 23 & 4.6 & 2.3 & $2-8$ \\
& NSs $(n=10)$ & 857 & 120 & 12 & 8.4 & $1-42$ \\
\hline
\end{tabular}

Table 4. Number of modalized utterances by group and by speaker (average).

It is clear that all eight groups use modalized forms in their narratives, although at different levels of frequency. We now turn to the profile of these forms, in order to examine their distribution across the two main semantic domains selected for this study: logical and personal meanings. Table 5 shows clearly the fact that all groups favor the use of personal over logical meaning. In the NS portions of our corpus, $70 \%$ (English) and $61.7 \%$ (French) of modalized utterances express personal meaning. Looking at the NNS portion of the corpus, we note that modalized forms with personal meanings are found at all levels. However, logical modal meanings are rare both in the lower intermediate narrations (only one instance in L2 English) and in the upper intermediate corpus (two examples each in L2 French and English). Logical modal meanings become more frequent in the narrations completed by the advanced learners, accounting for between $20.5 \%$ and $26.1 \%$ of their total modalized forms. We moreover note that the subjunctive mood in French makes its first appearance in the narratives produced by the advanced NNSs. 


\begin{tabular}{|c|c|c|c|c|c|c|c|c|}
\hline \multirow[b]{2}{*}{ Language } & \multirow[b]{2}{*}{ Group } & \multicolumn{2}{|c|}{ Logical } & \multicolumn{2}{|c|}{ Personal } & \multicolumn{2}{|c|}{ Subjunctive } & \multirow[b]{2}{*}{ Total } \\
\hline & & $n$ & $\%$ & $n$ & $\%$ & $n$ & $\%$ & \\
\hline \multirow[t]{5}{*}{ English } & NNSs & & & & & & & \\
\hline & Lower intermediate $(n=5)$ & 1 & $3.6 \%$ & 27 & $96.4 \%$ & - & - & 28 \\
\hline & Upper intermediate $(n=5)$ & 2 & $7.7 \%$ & 24 & $92.3 \%$ & - & - & 26 \\
\hline & Advanced $(n=5)$ & 8 & $20.5 \%$ & 31 & $79.5 \%$ & - & - & 39 \\
\hline & NSs $(n=10)$ & 48 & $30 \%$ & 112 & $70 \%$ & - & - & 160 \\
\hline \multirow[t]{5}{*}{ French } & NNSs & & & & & & & \\
\hline & Lower intermediate $(n=5)$ & - & - & 2 & $100 \%$ & - & - & 2 \\
\hline & Upper intermediate $(n=5)$ & 2 & $18.2 \%$ & 9 & $81.8 \%$ & - & - & 11 \\
\hline & Advanced $(n=5)$ & 6 & $26.1 \%$ & $15^{\mathrm{b}}$ & $65.2 \%$ & $2^{\mathrm{a}}$ & $8.7 \%$ & 23 \\
\hline & $\mathrm{NSs}(n=10)$ & 26 & $21.7 \%$ & $74^{\mathrm{b}}$ & $61.7 \%$ & $20^{\mathrm{a}}$ & $16.7 \%$ & 120 \\
\hline
\end{tabular}

Table 5. Distribution of modal verb forms across languages, proficiency levels and type of modality

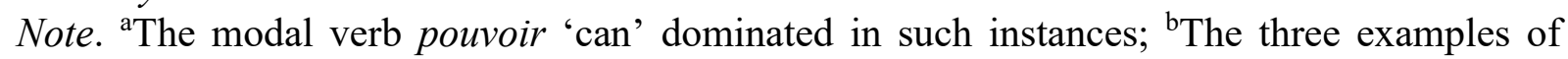
aimer 'like' in the conditional ( 1 among advanced learners and 2 produced by NSs) were coded as instances of personal modal meaning, expressing volition.

As regards semantic choices, Table 6 illustrates the fact that in our film-retelling task, certain modal meanings dominated. In the realm of logical modal meanings, NSs of English favoured certainty and prediction, while forms expressing necessity, inference and possibility were also found. NSs of French expressed prediction, necessity, possibility and certainty but not inference. Among the advanced and upper intermediate NNSs, we find forms expressing certainty, prediction and necessity in both French and English, and three examples of possibility in the advanced portion of the L2 English corpus. Most of these forms were associated with non-agentive subjects, with the notable exception of certainty ('I think'). Moving now to the most frequent category in the corpus - personal modal meaning - we note that, overall, participants primarily used modalized utterances involving agentive subjects in order to comment on the characters' ability to do something, their desires, and their intentions. The two NS sub-corpora were dominated by three meanings: ability/possibility, intention, and volition. Occurrences of two additional categories (obligation and permission) are also found in the English NS sub-corpora. Among the NNSs, expressions of ability/possibility, intention and volition are relatively common at all levels of proficiency and in the two languages. Expressions of obligation and permission are almost non-existent.

\begin{tabular}{|c|c|c|c|c|c|c|c|c|c|}
\hline \multirow[b]{2}{*}{ Meaning } & \multicolumn{4}{|c|}{ English } & \multicolumn{4}{|c|}{ French } & \multirow[b]{2}{*}{ Tota } \\
\hline & $\begin{array}{c}\text { NSs } \\
(n=10)\end{array}$ & $\begin{array}{c}\text { Advanc } \\
\text { ed }(n= \\
5)\end{array}$ & $\begin{array}{l}\text { Upp } \\
\text { inter }(n \\
=5)\end{array}$ & $\begin{array}{l}\text { Low. } \\
\text { Inter. }(n \\
=5)\end{array}$ & $\begin{array}{c}\text { NSs } \\
(n=10)\end{array}$ & $\begin{array}{c}\text { Advanc } \\
\text { ed }(n= \\
5)\end{array}$ & $\begin{array}{l}\text { Upp } \\
\text { inter }(n \\
=5)\end{array}$ & $\begin{array}{l}\text { Low } \\
\text { inter }(n \\
=5)\end{array}$ & \\
\hline Logical & & & & & & & & & 93 \\
\hline Prediction & 17 & 2 & 1 & & 13 & 2 & & & 35 \\
\hline Necessity & 3 & 2 & & & 8 & 3 & 1 & & 17 \\
\hline Inference & 6 & & & & & & & & 6 \\
\hline Possibility & 4 & 3 & 1 & & 4 & & & & 11 \\
\hline Certainty & 18 & 1 & & 1 & 2 & 1 & 1 & & 24 \\
\hline Personal & & & & & & & & & 307 \\
\hline Ability/possibility & 55 & 15 & 12 & 15 & 41 & 9 & 4 & & 151 \\
\hline
\end{tabular}




$\begin{array}{lccccccccc}\text { Intention } & 45 & 9 & 12 & 7 & 29 & 6 & 4 & 1 & 113 \\ \text { Volition } & 6 & 4 & & 5 & 15 & 1 & 1 & 1 & 33 \\ \text { Obligation } & 5 & 3 & & & & & & & 8 \\ \text { Permission } & 1 & & & & & & & & 1\end{array}$

Table 6. Modal semantic categories.

Finally, we examined the inventory of forms involved in modalized expressions in each of the eight sub-corpora. We first note that while the NSs of English and French employ the widest range of modality forms, as seen in the number of types found in the corpus (Table 7), mean use reveals that advanced NNS produce proportionally more types than NS. Concentrating on the L2 English data, we observe that lower and upper intermediate learners use a similar number of types and tokens, reflecting the use of a relatively varied set of modal forms, and that this inventory becomes more diverse at the advanced level. An examination of the different types shows that three forms are present in narrations from all groups including natives (can, try, decide). The advanced learners distinguish themselves from the intermediates, insofar as five new modal forms emerge in their narrations (keep, have to, might, would, will), each of which is also attested in the native sub-corpus. For the Englishspeaking learners of French, we see that the number and type of modal verbal forms increases as a function of proficiency, with lower intermediate learners barely using any modal forms. Similar to the English corpora, expression of ability/possibility (pouvoir 'can') and intention (essayer de 'try') are the most widespread forms throughout the French corpus, and it is especially at the advanced level that we see a development in the diversity of forms, with notably the addition of three new modal expressions (aller 'go', arriver à 'succeed', devoir 'must') and the subjunctive.

\begin{tabular}{llcccccccc}
\hline & & \multicolumn{2}{c}{$\begin{array}{c}\text { NSs } \\
\text { Language }\end{array}$} & Verb & \multicolumn{2}{c}{$\begin{array}{c}\text { Advanced } \\
(n=5)\end{array}$} & $\begin{array}{c}\text { Upper } \\
\text { intermediate } \\
(n=5)\end{array}$ & \multicolumn{2}{c}{$\begin{array}{c}\text { Lower } \\
\text { intermediate } \\
(n=5)\end{array}$} \\
\hline \multirow{2}{*}{ English } & Tokens & 160 & 16 & 39 & 7.8 & 26 & 5.2 & 28 & 5.6 \\
& Types & 16 & 1.6 & 11 & 2.2 & 7 & 1.4 & 7 & 1.4 \\
French & Tokens & 120 & 12 & 23 & 4.6 & 11 & 2.2 & 2 & 0.4 \\
& Types & 15 & 1.5 & 10 & 2 & 6 & 1.2 & 2 & 0.4 \\
\hline
\end{tabular}

Table 7. Modal forms used: Types and tokens

\section{Discussion and conclusion}

In this article, we set out to respond to two research questions. The first concerned if and how NSs and NNSs used modalized verb forms in a film retelling, whereas the second asked if and how modalization varies as a function of L2 proficiency level. In response to the first question, we saw that despite the fact that modality is most common "in face-to-face interactive discourse" (Bybee and Fleischman 1995: 8), NSs and NNSs of French and English used between $6.6 \%$ and $14 \%$ of modalized utterances when narrating a story. When we examined these forms more closely, we saw that personal meaning modals used to comment on the actions of the protagonists (ability/possibility) and on their states-of-mind 
(intention/volition) were by far the most frequent. An examination of the variety of verb forms used in modalized utterances revealed that NSs used more forms in total, although learners at advanced levels also showed a diverse inventory of forms and a higher mean type (see Table 7). Taken together, all eight groups use modalization in an oral narration task, although differences in number, meaning and types of modal verbal forms were clear across the groups.

Moving to the question of proficiency, several similar patterns were found in narrations from the English-speaking learners of French and the French-speaking learners of English. Lower intermediate NNSs of both languages restricted their use of verbal modal forms to the expression of two or three personal modal meanings, namely volition, intention, and ability/possibility. Although personal modal meanings remained frequent at the upper intermediate level, at this point the repertoires had expanded, and instances of logical personal meaning appeared. Among the advanced learners, logical modal meanings became more frequent and learners had greatly expanded the different semantic meanings expressed in their modal forms (see Table 6). It is also of note that among the advanced L2 French learners, we found two examples of the subjunctive mood and one of the conditional. Overall, these patterns mirror earlier findings, which showed personal modal meanings to appear before logical ones (e.g., Ahrenholz 2000), and reflect an increase in logical modal forms and the emergence of late-acquired features like the subjunctive at advanced levels of proficiency.

In what remains, we highlight two findings leading to new directions for future research. Starting with the predominance of personal modal meaning in all sub-corpora, we believe that this result may very well reflect discourse organization typical of narration. More specifically, expressions of personal modal meaning have the potential to appear in foreground utterances, which constitute the chronological backbone of the story. Although comments on events with modal forms such as can walk are usually expected to appear in background utterances, von Stutterheim (1993:14-17) states that "modalized utterances can be part of the storyline if they are referentially tied - in time, space, and person - to the narrative frame." She highlights the fact that modalized sentences (the dog has to throw, MIC, EngL1, utt 145) can be part of the storyline by means of implication: Thanks to the context, the hearer will assume that the dog has actually thrown (the scarf, in this instance). She adds that there can be no such implication with epistemic modals. In the context of the current analysis, logical meanings - mostly used with non-agentive subjects to express necessity, possibility, or inference - may be restricted to certain discursive functions. It may therefore be the case that they appear predominantly in background utterances. This would explain both the predominance of personal modal meaning in the narratives from the NSs and more advanced learners (insofar as the aim of a narrative is to push the story forward) and the absence of logical modal meaning among the lower intermediate learners, who may not yet have the competence (linguistic or discourse) to add background elements to their narratives, thus effectively excluding logical modal meanings. The potential link between modalization and discourse organization will need to be more closely examined in future research.

The second finding is linked to the crosslinguistic nature of our dataset. Indeed, the presence of learners acquiring two different L2s in a single analysis allows us to reflect on patterns in 
terms of whether they indicate language-specific tendencies or more general patterns of L2 acquisition. In our study, although clear patterns of development in the expression of modalization were seen between the upper intermediate and advanced groups in both English and French, striking differences were found across the two languages in the lower intermediate groups. Whereas the L2 English lower intermediates performed very similarly to the upper intermediates, in the French corpus, lower intermediate learners showed a different pattern, using only two modalized forms. These crosslinguistic differences suggest that early L2 acquisition of verbal modal forms may progress more quickly for English than for French. This pattern could be explained with recourse to language-specific information concerning the complexity of the French system: Not only are verbs used in the French modal system subject to the same conjugation requirements as lexical verbs, but many such verbs are irregular. If this interpretation is correct, we may expect that modal adverbials play a greater role in French interlanguage than in English. We hope to address this point in future research.

In her (2000) seminal volume on the acquisition of tense and aspect in SLA, Bardovi-Harlig observed that "work in the tense-aspect system in second language acquisition has generally avoided the second element in what is referred to as the "TMA" or "tense-mood-aspect" system" (2000: 417). We hope to have provided a few elements of linguistic description to address this gap.

\section{References}

Ahrenholz, Bernt. 2000. Modality and referential movement in instructional discourse. Studies in Second Language Acquisition 22. 337-368.

Ayoun, Dalila. 2013. The second language acquisition of French tense, aspect, mood and modality. Amsterdam: Benjamins.

Bardovi-Harlig, Kathleen. 2000. Tense and aspect in second language acquisition: Form, meaning and use. Oxford: Blackwell.

Bardovi-Harlig, Kathleen. 2002. A new starting point? Investigating formulaic use and input in future expression. Studies in Second Language Acquisition 24. 189-198.

Bartning, Inge. 2005. 'Je ne pense pas que ce soit vrai'. Le subjonctif un trait tardif dans l'acquisition du français L2. In Michael Metzeltin (ed.), Hommage à Jane Nystedt, 3149. Vienna: Drei Eidechsen.

Biber, Douglas, Susan Conrad \& Geoffrey Leech. 2002. Longman student grammar of spoken and written English. Harlow: Pearson Education Limited.

Bybee, Joan \& Suzanne Fleischman. 1995. Modality in grammar and discourse: an introductory essay. In Joan Bybee \& Suzanne Fleischman (eds.), Modality in grammar and discourse, 1-14. Amsterdam: Benjamins.

Choi, Soonja. 2006. Acquisition of modality. In William Frawley (ed.), The expression of modality, 141-171. Berlin: Mouton de Gruyter.

Dittmar, Norbert. 1993. Proto-semantics and emergent grammars. In Norbert Dittmar \& Astrid Reich (eds.), Modality in language acquisition/modalité et acquisition des langues, 213-233. Berlin: Walter de Gruyter.

Ducrot, Oswald. 1993. A quoi sert le concept de modalité? In Norbert Dittmar \& Astrid Reich (eds.), Modality in language acquisition/modalité et acquisition des langues, 111-129. Berlin: Walter de Gruyter. 
Edmonds, Amanda \& Aarnes Gudmestad. 2015. What the present can tell us about the future: a variationist analysis of future-time expression in native and non-native French. Language, Interaction and Acquisition 6(1). 15-41.

Giacalone Ramat, Anna. 1995. Function and form of modality in learner Italian. In Anna Giacalone Ramat \& Grazia Crocco Galèas (eds.), From pragmatics to syntax: Modality in second language acquisition, 269-293. Tübingen: Gunter Narr Verlag.

Gibbs, Dorothy A. 1995. Second language acquisition of the English modal auxiliaries can, could, may, and might. Applied Linguistics 11. 297-314.

de Haan, Ferdinand. 2006. Typological approaches to modality. In William Frawley (ed.), The expression of modality, 27-69. Berlin: Mouton de Gruyter.

Howard, Martin. 2008. Morpho-syntactic development in the expression of modality: The subjunctive in French L2 acquisition. Canadian Journal of Applied Linguistics 11. 171-192.

Howard, Martin. 2012. From tense and aspect towards modality - the acquisition of future, conditional and subjunctive morphology in L2 French. A preliminary study. In Emmanuelle Labeau \& Ines Saddour (eds.), Tense, aspect and mood in first and second language acquisition, 201-223. New York: Rodopi.

Howard, Martin \& Pascale Leclercq. 2017. Introduction. Tense, aspect and modality in second language acquisition: An overview. In Martin Howard \& Pascale Leclercq (eds.), Tense-Aspect-Modality in a second language. Perspectives on French and English, 1-25. Amsterdam: Benjamins.

Lepetit, Daniel. 2001. Subjonctif: descriptions et manuels. The French Review 74. 1176-1192.

McManus, Kevin \& Rosamond Mitchell. 2015. Subjunctive use and development in French L2: a longitudinal study. Language, Interaction and Acquisition 6(1). 42-73.

Nuyts, Jan. 2006. Modality: Overview and linguistic issues. In William Frawley (ed.), The expression of modality, 1-26. Berlin: Mouton de Gruyter.

Poplack, Shana, Allison Lealess \& Nathalie Dion. 2013. The evolving grammar of the French subjunctive. Probus 25. 139-195.

Salsbury, Tom \& Kathleen Bardovi-Harlig. 2000. Oppositional talk and the acquisition of modality in L2 English. In Bonnie Swierzbin, Frank Morris, Michael Anderson, Carol Klee \& Elaine Tarone (eds.), Social and cognitive factors in second language acquisition, 57-76. Somerville: Cascadilla Press.

Stephany, Ursula. 1993. Modality in first language acquisition: The state of the art. In Norbert Dittmar \& Astrid Reich (eds.), Modality in language acquisition/modalité et acquisition des langues, 133-144. Berlin: Walter de Gruyter.

Stephany, Ursula. 1995. Function and form of modality in first and second language acquisition. In Anna Giacalone Ramat \& Grazia Crocco Galèas (eds.), From pragmatics to syntax: Modality in second language acquisition, 105-120. Tübingen: Gunter Narr Verlag.

Stoffel, Henriette \& Daniel Véronique. 1993. Acquisition de modalités en français et procès de modalisation chez des adultes arabophones marocains. In Norbert Dittmar \& Astrid Reich (eds.), Modality in language acquisition/modalité et acquisition des langues, 277-296. Berlin: Walter de Gruyter.

Von Stutterheim, Christiane. 1993. Modality: Function and form in discourse. In Norbert Dittmar \& Astrid Reich (eds.), Modality in language acquisition/modalité et acquisition des langues, 3-26. Berlin: Walter de Gruyter.

Watorek, Marzena (ed.). 2004. Construction du discours par des enfants et des apprenants adultes. Langages 155. 